ISSN 0258-7122 (Print), 2408-8293 (Online)

Bangladesh J. Agril. Res. 41(3): 387-396, September 2016

\title{
ASSOCIATION OF YIELD AND YIELD RELATED TRAITS IN AROMATIC RICE (Oryza sativa L.)
}

\author{
A. H. AKHI ${ }^{1}$, M. A. K. $\mathrm{MIAH}^{2}$, N. A. IVY ${ }^{3}$ \\ A. ISLAM ${ }^{4}$ AND M. Z. ISLAM ${ }^{5}$
}

\begin{abstract}
Sixty cross combinations of SakkhorkhoraR and IR58025A were studied in the experimental field of Bangabundhu Sheikh Mujibur Rahman Agricultural University (BSMRAU), Salna, Gazipur during July 2010 to November 2010, to assess the character association \& contribution of characters towards grain yield in restorer lines. The correlation study revealed that days to first flowering showed significant positive relationship with seed yield per plant at genotypic levels. Days to maturity showed significant positive relationship with number of tillers per plant at both genotypic and phenotypic level and effective panicles per plant at genotypic level. Plant height showed highly significant positive relationship with effective panicles per plant at both genotypic and phenotypic level. Path analysis study revealed that effective panicles per plant $(0.2153)$ had the highest positive direct effect followed by days to first flowering (0.1492), plant height (0.0646), spikelet fertility status (\%) (0.0242) and number of seeds per panicle (0.0241). Days to maturity, spikelet sterility status, effective panicles per plant, plant height, number of tillers per plant, number of seeds per panicle and spikelet fertility status had positive indirect effects on grain yield. So, based on the study days to first flowering, plant height, spikelet fertility status ,effective panicles per plant were identified as the important characters to be considered in the selection for improvement of aromatic rice genotypes.
\end{abstract}

Keywords: aromatic rice, character association, path analysis.

\section{Introduction}

Rice is tolerant to hot, humid, flooded and dry conditions, and grows in saline, alkaline and acidic soils. Asian cultivated rice has evolved into three ecogeographic races - indica, japonica and javanica (Jason et al., 2006). Rice is the staple food for at least $63 \%$ of our planet inhabitants and contributes on an average $20 \%$ of apparent calorie intake of the world population and $30 \%$ of population in Asia (Calpe and Prakash, 2007). Among the 150 different crops grown in Bangladesh, rice alone occupies about $77 \%$ of the total cultivated area, of which aromatic rice is cultivated only on the $10 \%$ of the rice growing area (Anon., 2008). In Bangladesh, more than four thousand landraces of rice are

\footnotetext{
${ }^{1}$ Scientific Officer, Plant Breeding Division, Bangladesh Agricultural Research Institute (BARI), Gazipur, ${ }^{2 \& 3}$ Professor, Dept. of Genetics and Plant Breeding, Bangabandhu Sheikh Mujibur Rahman Agricultural University (BSMRAU), Gazipur-1706, ${ }^{4}$ Senior Scientific officer, RARS, BARI, Hathazari, Chittagong, ${ }^{5}$ Scientific officer, Genetic Resources and Seed Division, BRRI, Gazipur, Bangladesh.
} 
adopted in different parts of this country (Sajib et al., 2012). Some of these are unique for quality traits including fineness, aroma, taste and fine contents. A group of such rice is known as aromatic rice. Among the rice varieties, aromatic rice is popular in Asia and gained wider acceptance in Europe and the United States because of their aroma, flavor and texture. Aromatic rice is known for its characteristics fragrance after being cooked. This constitutes a small but special group of rice, which is considered best in quality. The natural chemical compound that is 2-acetyl-1-pyroline gives aromatic rice the characteristic aroma and flavor but in the aromatic varieties it is present in much higher concentrations (Faridah et al., 2011). The demand for aroma rice is increasing day by day. Unfortunately, the aromatic rice often has undesirable agronomic characters, such as low yield, susceptibility to pests and diseases, and strong shedding (Faruq et al., 2011).

Breeding strategies should emphasise on aromatic rice production. Yield is a quantitative trait, greatly influenced by environmental fluctuations. Study on yield contributing characters assumes greater importance of fixing up characters that influence yield (Faruq et al., 2011). For the development of a high yielding genotype through breeding rice requires a thorough knowledge of the association of the yield components. Correlation analysis provides a good measure of the association between characters and helps to identify the most important character(s) to be considered for effective selection for increasing yield. However, simple correlation does not provide adequate information about contribution of each factor towards yield (Nandan et al., 2010). Therefore the technique of path coefficient analysis is utilized to have an idea of direct and indirect contribution of a trait towards yield, the end product. The present study was undertaken to gather some useful information on character association and path coefficient analysis in a set of $60 \mathrm{~F}_{1}$ families of aromatic rice genotypes.

\section{Materials and Method}

The experiment was conducted at the experimental farm of BSMRAU during July 2010 to November 2010. Sixty $F_{1}$ (IR58025A x Sakkorkhora R) families of aromatic rice genotypes were planted in randomized complete block design with three replication at the rate of one seedling per hill. Each entry was planted in one rows of $5 \mathrm{~m}$ long plot with a spacing of $20 \mathrm{~cm} \times 20 \mathrm{~cm}$ from plant to plant and row to row respectively. Adequate soil fertility was ensured by applying urea, TSP, MoP and Gypsum @ 180-100-70-60 kg/ha, respectively. Total TSP, MoP and Gypsum were applied in final land preparation. And total urea was applied in three installments, at 15 days after transplanting (DAT), 30 DAT and 50 DAT recommended by Anon. (1999). After transplanting various intercultural operations and irrigation were applied for better growth and development of the seedlings. Data were recorded on the parameters from 5 randomly selected plants from the middle rows of each plot on days to first flowering, days to maturity, 
plant height $(\mathrm{cm})$, number of tillers per plant, number of effective panicles per plant, spikelet fertility status (\%), spikelet sterility status (\%), number of seeds per panicle, seed yield per plant (g). For calculating the genotypic and phenotypic correlation co-efficient for all possible combinations the formula suggested by Miller et al. (1958), Johnson et al. (1955) and Hanson et al. (1956) were adopted. Path coefficient analysis was done according to Dewey and Lu (1955).

\section{Results and Discussion}

Association study revealed that the genotypic and the phenotypic correlation coefficients showed similar trend but genotypic correlation coefficients were of higher in magnitude than the corresponding phenotypic correlation coefficients (Table 1). It may be due to the masking or modifying effect of environment on character association at the genetic level (Singh, 1980; Sarawgi et al., 1997).

Days to first flowering showed significant positive relationship with seed yield per plant at genotypic levels. It was found to display highly significant positive relationships with days to maturity at both genotypic and phenotypic level but showed insignificant positive correlation with number of tillers per plant, effective panicles per plant and spikelet sterility status at both genotypic and phenotypic level. Similar findings were reported by Satyanarayan et al. (2005) for panicle length, number of grains per panicle and number of effective tillers per plant. Days to maturity, plant height $(\mathrm{cm})$, number of tillers per plant, number of effective panicles per plant, spikelet fertility status (\%) showed insignificant positive correlation with seed yield per plant and spikelet sterility status (\%), number of seeds per panicle showed insignificant negative correlation with seed yield per plant (g) (Table 1). Suprio et al. (2010) found yield per plant showed significant positive correlation with plant height, panicle length, effective grains per panicle and harvest index.

Days to maturity showed significant positive relationship with number of tillers per plant at both genotypic and phenotypic level and effective panicles per plant at genotypic level (Table 1). And the genotypic value (0.303) is higher than the phenotypic value $(0.256)$ which indicate that there is a strong association between these two characters genetically but the phenotypic value is lessened by the significant interaction of environment. Qamar et al. (2005) exhibited positive and non-significant correlation with productive tillers per plant at both levels.

Plant height showed highly significant positive relationship with effective panicle per plant at both genotypic and phenotypic level. Suprio et al. (2010) found effective grains per panicle revealed significant positive relationship with plant height. It indicated that increasing plant height caused to increase effective panicles per plant. The character also showed insignificant positive relationship with spikelet sterility status, number of seeds per panicle and seed yield per plant both at genotypic and phenotypic level (Table_1). Similar findings were reported by Sarkar et al. (2001). 


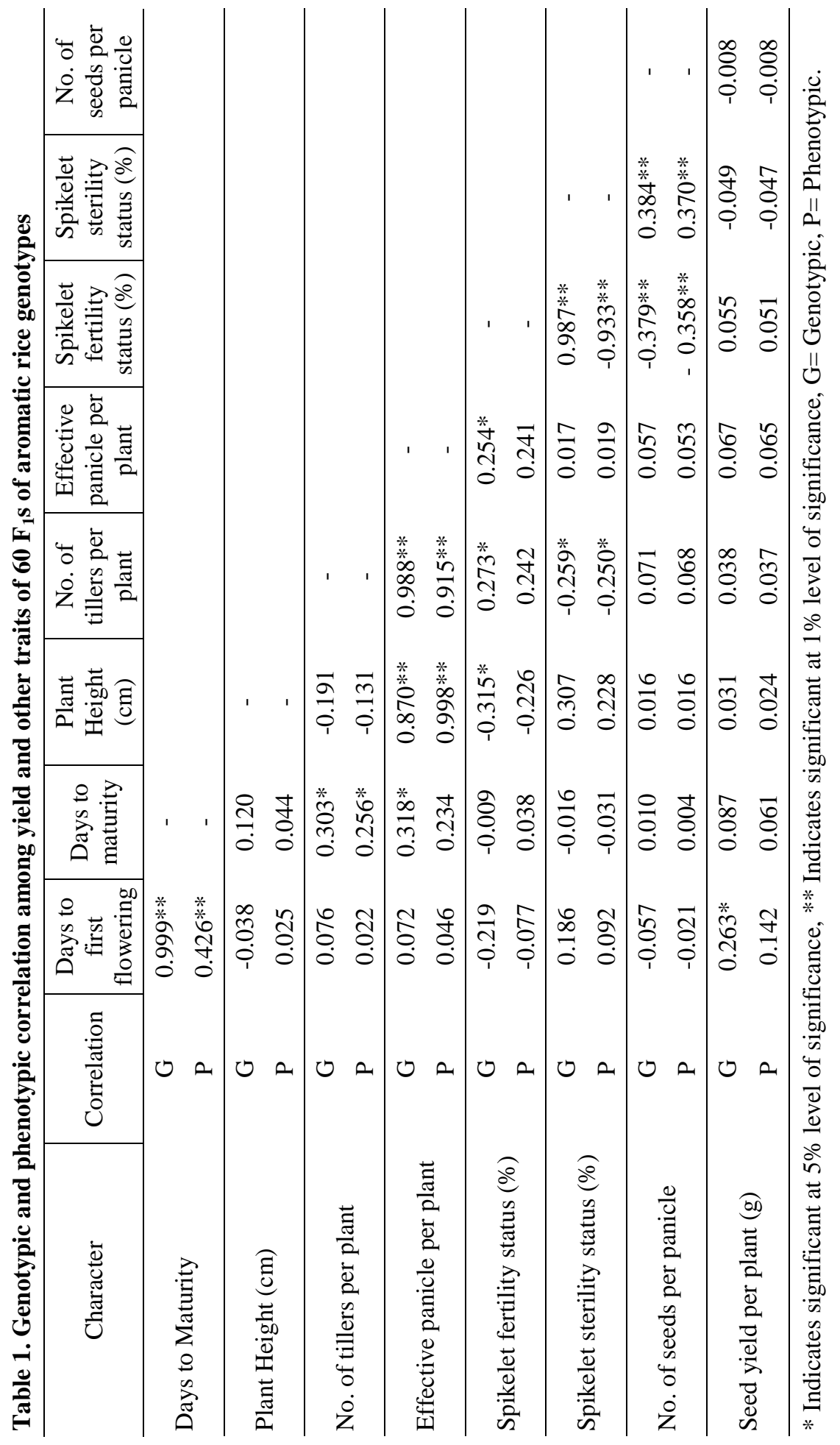


ASSOCIATION OF YIELD AND YIELD RELATED TRAITS IN AROMATIC RICE

\begin{tabular}{|c|c|c|c|c|c|c|c|c|c|c|}
\hline 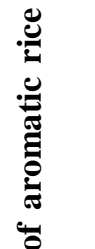 & 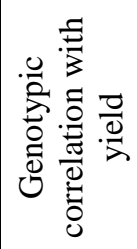 & $\frac{⿱ 亠 ⿻}{J}$ & 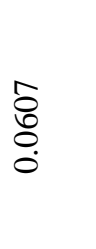 & 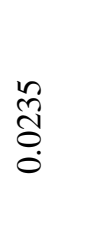 & $\begin{array}{l}n \\
0 \\
0 \\
0 \\
0\end{array}$ & 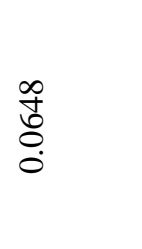 & $\frac{N}{n}$ & \begin{tabular}{l}
$n$ \\
\multirow{8}{0}{} \\
0 \\
0
\end{tabular} & $\begin{array}{l}0 \\
5 \\
0 \\
0 \\
1\end{array}$ & \\
\hline 5 & 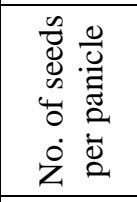 & \begin{tabular}{l}
$n$ \\
8 \\
8 \\
\hdashline \\
$\dot{1}$
\end{tabular} & $\begin{array}{l}\overline{8} \\
8 \\
0\end{array}$ & $\begin{array}{l}0 \\
\delta \\
0 \\
0\end{array}$ & $\begin{array}{l}0 \\
\stackrel{0}{8} \\
0 \\
0\end{array}$ & $\stackrel{m}{\frac{m}{8}}$ & $\begin{array}{l}0 \\
\infty \\
8 \\
0 \\
\dot{0}\end{array}$ & $\begin{array}{l}\infty \\
\infty \\
8 \\
0\end{array}$ & 芩 & \\
\hline 选 & 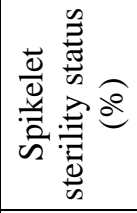 & $\begin{array}{l}\stackrel{9}{\Phi} \\
\stackrel{8}{8} \\
\dot{9}\end{array}$ & $\frac{\infty}{8}$ & $\begin{array}{l}0 \\
\stackrel{2}{0} \\
0 \\
\dot{0}\end{array}$ & $\begin{array}{l}0 \\
\stackrel{0}{0} \\
0 \\
0\end{array}$ & 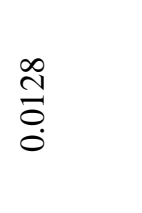 & $\begin{array}{l}\frac{a}{n} \\
0 \\
0\end{array}$ & $\begin{array}{l}0 \\
n \\
n \\
0 \\
0\end{array}$ & 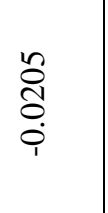 & \\
\hline อ̊ํㅇ & 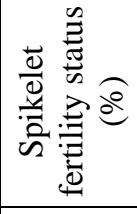 & $\begin{array}{l}\infty \\
\stackrel{0}{8} \\
\stackrel{0}{\varphi}\end{array}$ & $\begin{array}{l}8 \\
8 \\
8 \\
0\end{array}$ & $\begin{array}{l}\stackrel{+}{~} \\
\text { } \\
0 \\
0\end{array}$ & 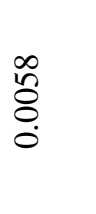 & $\begin{array}{l}\infty \\
\stackrel{2}{8} \\
\ddot{0}\end{array}$ & 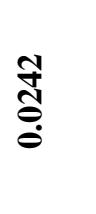 & 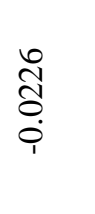 & $\begin{array}{l}\hat{\infty} \\
8 \\
0 \\
0\end{array}$ & \\
\hline $\begin{array}{l}\stackrel{ }{. \Xi} \\
\frac{\partial}{0} \\
\frac{0}{2}\end{array}$ & 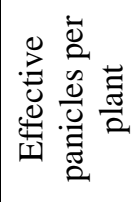 & $\begin{array}{l}\circ \\
8 \\
8 \\
0\end{array}$ & 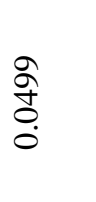 & $\begin{array}{l}\infty \\
a \\
0 \\
0\end{array}$ & $\frac{5}{3}$ & $\frac{\text { ñ }}{\text { กุ }}$ & $\begin{array}{l}\frac{J}{n} \\
0 \\
0\end{array}$ & $\begin{array}{l}\hat{a} \\
\hat{0} \\
\dot{0}\end{array}$ & $\stackrel{\Xi}{\Xi}$ & $\begin{array}{l}\stackrel{2}{a} \\
\stackrel{+}{+} \\
\text { II } \\
\simeq\end{array}$ \\
\hline $\begin{array}{l}50 \\
=5\end{array}$ & 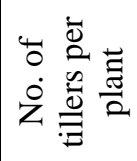 & 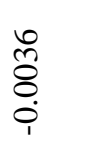 & $\begin{array}{l}\stackrel{2}{\sigma} \\
\text { ọ } \\
\text { i }\end{array}$ & 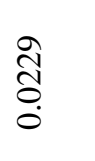 & $\frac{\vec{N}}{\frac{1}{9}}$ & $\frac{n}{n}$ & \begin{tabular}{l}
$n$ \\
\multirow{J}{0}{} \\
$\dot{0}$
\end{tabular} & 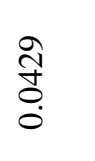 & $\begin{array}{l}0 \\
0 \\
0 \\
0 \\
1\end{array}$ & \\
\hline$\overline{\frac{\pi}{d}}$ & 芯 离 & $\frac{\infty}{8}$ & $\begin{array}{l}\stackrel{\overbrace{}}{8} \\
\stackrel{0}{0}\end{array}$ & \begin{tabular}{l}
0 \\
\multirow{0}{0}{} \\
0
\end{tabular} & $\begin{array}{l}0 \\
0 \\
8 \\
0 \\
0 \\
1\end{array}$ & $\begin{array}{l}\stackrel{g}{ \pm} \\
\stackrel{0}{0} \\
\dot{1}\end{array}$ & $\begin{array}{l}\underset{ \pm}{\Xi} \\
0 \\
0\end{array}$ & 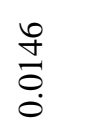 & $\begin{array}{l}\stackrel{0}{8} \\
\stackrel{8}{0}\end{array}$ & \\
\hline : & 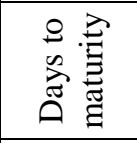 & $\begin{array}{l}\infty \\
\infty \\
8 \\
0 \\
\dot{0}\end{array}$ & $\stackrel{\infty}{0}$ & $\begin{array}{l}9 \\
8 \\
8 \\
\\
\end{array}$ & 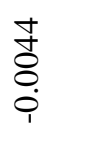 & $\begin{array}{l}\text { サ } \\
\stackrel{0}{0} \\
\end{array}$ & $\begin{array}{l}\infty \\
8 \\
8 \\
0 \\
1\end{array}$ & $\begin{array}{l}8 \\
8 \\
8 \\
0\end{array}$ & $\begin{array}{l}\overline{8} \\
8 \\
\end{array}$ & \\
\hline 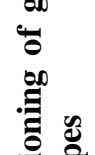 & 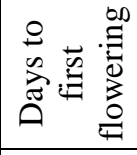 & $\frac{\check{g}}{\dot{\Xi}}$ & $\begin{array}{l}\infty \\
\text { ñ } \\
\stackrel{0}{0} \\
0\end{array}$ & $\begin{array}{l}\stackrel{N}{\Im} \\
\stackrel{\delta}{0}\end{array}$ & $\begin{array}{l}\bar{\kappa} \\
\stackrel{8}{0}\end{array}$ & $\begin{array}{l}n \\
8 \\
8 \\
0\end{array}$ & $\begin{array}{l}Z \\
\overline{0} \\
0\end{array}$ & $\stackrel{+}{\stackrel{m}{0}}$ & 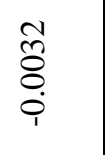 & \\
\hline 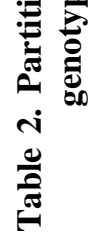 & 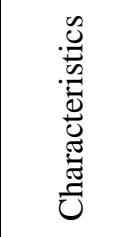 & 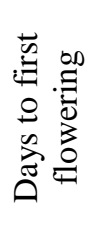 & 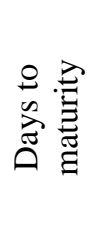 & 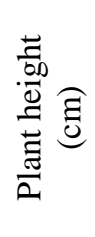 & 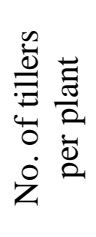 & 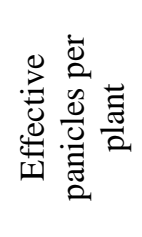 & 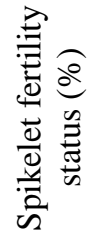 & 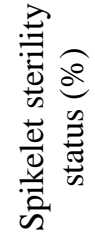 & 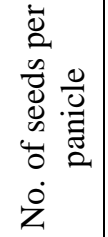 & \\
\hline
\end{tabular}


Number of tillers per plant showed highly significant positive correlation with effective panicle per plant at both genotypic and phenotypic level and showed significant positive correlation with spikelet fertility status at genotypic level. The results are in supported by Mulugeta et al. (2012). Highly significant positive correlation between two traits indicated the traits are governed by same gene and simultaneous improvement would be effective. It also showed significant negative relationship with spikelet sterility status at both genotypic and phenotypic level. Effective panicle per plant showed significant positive relationship with spikelet fertility status at genotypic level. Kole et al. (2008) obtained significant negative corrrelation with panicle number and spikelet fertility status (\%). Spikelet fertility status showed highly significant negative relationship with number of seeds per panicle at both genotypic and phenotypic level. The results are in agreement with Kole et al. (2008) for grain number and spikelet fertility status (\%). Spikelet sterility status (\%) showed highly significant positive relationship with number of seeds per panicle (Table 1).

Significant negative corrrelations were also noted for spikelet fertility status (\%) with plant height at genotypic level (Kole et al. 2008). The observed significant negative correlation in spikelet sterility status (\%) with number of tillers per plant at both genotypic and phenotypic level which was supported by earlier workers, Ekka et al. (2011). They showed negative correlation in spikelet sterility status (\%) with number of effective tillers per plant at both genotypic and phenotypic level. The phenotypic correlation between spikelet sterility status (\%) vs. spikelet fertility status(\%) were negative and significant at $1 \%$ level. The results are in agreement with Karim et al. (2014) for 1000 grain weight and spikelet sterility status $(\%)$. Pleiotrophy and/or linkage may also be genetic the reason for this type of negative association. According to NeWall and Eberhart (1961), when two characters show negative phenotypic and genotypic correlation it would be difficult to exercise simultaneous selection for these characters in the development of a variety. Hence, under such situations, judicious selection programme might be formulated for simultaneous improvement of such important developmental and component characters (Table 1).

\section{Path analysis}

Considering grain yield as effect and eight characters as causes, genotypic correlation coefficient were partitioned by using method of path analysis to find out the direct and indirect effects of yield contributing characters towards grain yield. The results of path analysis presented in Table- 2 revealed that the effective panicles per plant $(0.2153)$ had the highest positive direct effect on yield followed by days to first flowering (0.1492), plant height (0.0646), spikelet fertility status $(\%)(0.0242)$ and number of seeds per panicle (0.0241) indicating that these are the main contributiors to yield. The findings were supported by 
Mulugeta et.al.(2012) for grains per panicle (2.226) followed by days to $50 \%$ flowering (1.465), panicle length (0.641), total spikelet fertility $(0.269)$ and plant height (0.087).

Effective panicles per plant showed the highest positive direct effect $(0.2153)$ on yield (Table 2). This findings is in agreement with Kole et al. (2008). This character also showed the highest positive indirect effect through spikelet sterility status $(0.0128)$ followed by days to first flowering (0.0065), spikelet fertility status (0.0058) and number of seeds per panicle (0.0013). The character produced the negative indirect effect on number of tillers per plant $(-0.1575)$ followed by plant height (-0.0149) and days to maturity (-0.0044) (Table 2). Mulugeta et al. (2012) reported similar finding for tillers per plant. Since the direct effect and correlation coefficient between effective panicles per plant and grain yield are positive, so it is an indication of true relationship among these traits. It suggests that the direct selection for effective panicles per plant would likely to be effective in improving the grain yield. Qamar et al. (2005) reported positive contribution of total spikelets towards grain yield, which supports the present finding.

Days to first flowering showed the positive direct effect (0.1492)) on yield (Table 2). Similar findings were reported by Kishore et al. (2007). The character also showed the maximum positive indirect effect through effective panicles per plant (0.0096) followed by plant height (0.0018). The character also produced the negative indirect effect on yield via days to maturity $(-0.0081)$, spikelet sterility status (0.0049), number of tillers per plant (-0.0036), spikelet fertility status (-0.0018) and number of seeds per panicle (0.0005).

Plant height showed the positive direct effect (0.0646) on yield (Table 2). Similar findings were reported by Kole et al. (2008). The character also showed the maximum positive indirect effect through number of tillers per plant (0.0229), followed by days to first flowering (0.0042) and number of seeds per panicle $(0.0003)$. The character also produced the negative indirect effect on effective panicles per plant (-0.0498), spikelet sterility status (-0.0126), spikelet fertility status (0.0058) and days to maturity $(-0.0009)$.

Spikelet fertility status showed the positive direct effect (0.0242) on yield (Table 2). This character also showed the highest positive indirect effect through spikelet sterility status (0.0519) followed by effective panicles per plant (0.0514). The character produced the negative indirect effect on number of tillers per plant $(-0.0415)$, plant height $(-0.0144)$, days to first flowering ($0.0111)$, number of seeds per panicle $(-0.0086)$ and days to maturity $(-0.0008)$.

Number of seeds per panicle showed the positive direct effect (0.0241) on yield (Table 2). Similar findings were reported by Mustafa and Elsheikh (2007) and Akinwale et al. (2011).This character also showed the highest positive indirect 
effect through effective panicles per plant (0.0114), followed by plant height (0.0010). The character produced the negative indirect effect on spikelet sterility status $(-0.0205)$, followed by spikelet fertility status $(-0.0087)$, number of tillers per plant (-0.0116), days to first flowering $(-0.0032)$, days to maturity $(-0.0001)$.

Days to maturity, number of tillers per plant, spikelet sterility status (\%) had very low negative direct effect on grain yield. Moreover the contribution of these three characters in the path way of other characters was negligible.

The residual effect was 0.4953 indicated that the contribution of component characters on grain yield was $50.47 \%$ by the eight characters studied in path analysis, the rest $49.53 \%$ was the contribution of other factors, not included in this study.

\section{Conclusion}

It is obvious from the results that the traits effective panicles per plant had the highest positive direct effect on yield and positive genotypic association as well with grain yield. And other traits such as days to first flowering, plant height, spikelet fertility status (\%) do have high positive direct effect and positive genotypic association as well with grain yield. So these parameters may be given prime importance for the direct improvement of grain yield in this group. Number of seeds per panicle showed the high positive direct effect but this parameter has negative genetic association.

\section{References}

Akinwale, A. G., G. Gregorio, F. Nwilene, B. O. Akinyele, S. A. Ogunbayo and A. C. Odiyi. 2011. Heritability and correlation coefficient analysis for yield and its components in rice (Oryza sativa L.). African J. Plant Sci. 5: 207-212.

Anonymous. July 2008 - June 2009. Annual research review workshop, BRRI.

Anonymous, 1999. Annual report for 1999. Bangladesh Rice Research Inst. Gazipur, p.29.

Calpe, C. and A. Prakash. 2007. Sensitive and Special Products-a rice perspective. Commodity Market Review, FAO. Pp. 49-71.

Dewey, D. R. and K. H. Lu. 1955. A correlation and path coefficient analysis of components of crested wheat grass seed production. Agron. J. 51: 515-518.

Ekka, R. E., A. K. Sarawgi and R. R. Kanwar. 2011. Correlation and Path Analysis in Traditional Rice Accessions of Chhattisgarh. Journal of Rice Research. 4: 1 \& 2

Faridah, Y., P. J. Fryer and S. Baklis. 2011. The absorption of 2-acetyl-1-pyrroline during cooking of rice (Oryza sativa L.) with Pandan (Pandanus amaryllifolius Roxb.) leaves . Procedia Food Science 1: $722-728$. 
Faruq, G. Y., Y. Hui. A. Masitah, N. Afnierna, N. A. Majid, N. Khalid and M. Osman. 2011. Analysis of aroma and yield components of aromatic rice in Malaysian tropical environment. AJCS 5(11): 1318-1325.

Hanson, C. H., H. F. Robinson. and R. E. Comstock. 1956. Biometrical studies of yield in Segregation population of Korean Lespedza. Agron J. 48: 268 -272.

Johnson, H. W., H. F. Robinson. and R. E. Comstock. 1955. Estimates of genetic and environmental variability in Soybean. Agron. J. 47: 314-318.

Jason, P.L., Y. C. Chiang, K. H. Hung, T.Y. Chiang and B. A. Schall. 2006. Phylogeography of Asian wild rice, Oryza rufipogon, reveals multiple independent domestications of cultivated rice, Oryza sativa.PNAS. 103(25): 9578-9583.

Karim, D., N.A. Siddique,U.Sarkar,M.Z.Hasnat and J.Sultana. 2014. Phenotypic and genotypic correlation co-efficient of quantitative characters and character association of aromatic rice. Journal of Bioscience and Agriculture Research. 01(01): 34-46.

Kishore, N. S., V. R. Ansaril, V. R. Babu, N. S. Rani, L. V. S. Rao. and Ravichandran. 2007. Correlation and path coefficient analysis in aromatic and non aromatic genotypes. Agricultural Science Digest. 27(2):122-124.

Kole, P. C., N. R Chakraborty and J. S. Bhat. 2008. Analysis of variability, correlation and path coefficients in induced mu-tants of aromatic non-basmati rice. Tropical Agricultural Research \& Extension.

Miller, P. J., J. C. Williams, H. F. Robinson and R. E. Comstock. 1958. Estimation of genotypic and environmental variance and co-variance in upland cotton and their implications in selection . Agron. J. 50 (2): $126-131$.

Mulugeta, S., A. Sentayehu. and B. Kassahun. 2012. Genetic Variability, Heritability, Correlation Coefficient and Path Analysis for Yield and Yield Related Traits in Upland Rice (Oryza sativa L.). Journal of Plant Sciences 7: 13-22.

Mustafa, M. A. and M. A. Y. Elsheikh. 2007. Variability, correlation and path coefficient analysis for yield and its components in rice. Afr. J. of Crop Sci. 15: 183-189.

NeWall, L. C. and S. A. Eberhart. 1961. Clone and progeny evaluation in the improvement in the improvement of switch grass (Panicum virgatum L.). Crop Sci. 1: $117-121$.

Nandan, R., Sweta and S.K. Singh. 2010. Character Association and Path Analysis in Rice (Oryza sativa L. ) Genotypes.World Journal of Agricultural Sciences 6(2): 201206.

Qamar, Z., A. A. Cheema, M. Ashraf, M. Rashid and G. R. Tahir. 2005. Association analysis of some yield influencing traits in aromatic and non aromatic rice. Pak. $J$. Bot. 37(3): 613-627.

Satyanarayana, P. V., T. Srinvias, P. R. Reddy, L. Madhavilatha. and Y. Suneetha. 2005. Studies on variability, Correlation and path coefficient analysis for restorer lines in rice (Oryza sativa L.). Research on Crops. 6(1): 80-84.

Sarawgi, A. K., N. K. Rastogi. and D. K. Soni. 1997. Correlation and path analysis in rice accessions from Madhya Pradesh. Field Crops Res. 52: 161-167. 
Sajib, A. M., M. M. Hossain, A. T. M. Z. Mosnaz, H. Hossain, M. M. Islam, M. s. Ali and S. H. Prodhan. 2012. SSR marker-based molecular characterization and genetic diversity analysis of aromatic landraces of rice (Oryza sativa L.) J. BioSci. Biotech. 1(2): 107-116

Singh, R. P. 1980. Association of grain yield and its component in F1 and F2 population of rice. Oryza. 17: 200-204.

Suprio, C., K. D. Pradip, G. Biswajit, K. S. Kalyan. and B. Bhubaneswar. 2010. Quantitative Genetic Analysis For Yield And Yield Component In Rice. Not Sci. Biol. 2(1): 117-120.

Sarkar, U., P. S. Biswas, B. Prasad. and M. A. K. Mian. 2001. Correlation response, relative selection efficiency and path analysis in cold tolerant rice. Bangladesh J. of Pl. Breed \& Genet. 14(2): 33-36. 